\title{
APPLICATION OF THE GARRLIC ALGORITHM FOR THE CHARACTERIZATION OF DUST AND MARINE PARTICLES UTILIZING THE LIDAR-SUNPHOTOMETER SYNERGY
}

\author{
Alexandra Tsekeri ${ }^{1 *}$, Vassilis Amiridis ${ }^{1}$, Anton Lopatin ${ }^{2}$, Eleni Marinou ${ }^{1}$, Panos Kokkalis ${ }^{1}$, Stavros \\ Solomos $^{1}$, Ronny Engelmann ${ }^{3}$, Holger Baars ${ }^{3}$, Ulla Wandinger ${ }^{3}$, Albert Ansmann ${ }^{3}$, Dirk \\ Schüttemeyer $^{4}$ and Oleg Dubovik ${ }^{2}$ \\ ${ }^{1}$ IAASARS, National Observatory of Athens, Athens, Greece, *Email: atsekeri@noa.gr \\ ${ }^{2}$ Laboratoire d' Optique Atmosphérique, Universite de Lille, Lille, France \\ ${ }^{3}$ Leibniz Institute for Tropospheric Research, Leipzig, Germany \\ ${ }^{4}$ European Space Agency, Netherlands
}

\begin{abstract}
The importance of studying the vertical distribution of aerosol plumes is prominent in regional and climate studies. The new Generalized Aerosol Retrieval from Radiometer and Lidar Combined data algorithm (GARRLiC) provides this opportunity combining active and passive ground-based remote sensing from lidar and sunphotometer measurements. Here, we utilize GARRLiC capabilities for the characterization of Saharan dust and marine particles at the Eastern Mediterranean region during the Characterization of Aerosol mixtures of Dust And Marine origin Experiment (CHARADMExp). Two different case studies are presented, a dust-dominated case which we managed to characterize successfully in terms of the particle microphysical properties and their vertical distribution and a case of two separate layers of marine and dust particles for which the characterization proved to be more challenging.
\end{abstract}

\section{INTRODUCTION}

Information about aerosol characterization is becoming an important topic in the context of current and future Earth Observation missions (e.g Flex, CarbonSat, EARTHCARE, ADM-Aeolus missions of the European Space Agency (ESA)). The CHARADMExp campaign (http://charadmexp.gr) was funded by ESA and was held in June and July 2014 to study the optical, microphysical and chemical properties of the Saharan dust and marine particles, as the most abundant aerosols of Eastern Mediterranean. The campaign was located in the remote Finokalia station, which belongs to the Aerosols, Clouds, and Trace gases Research InfraStructure Network
(ACTRIS - http://www.actris.net/), and its location provides favorable conditions for unobstructed monitoring of marine, dust and smoke particles along with their mixtures.

The GARRLiC algorithm [1] was used for the analysis of the campaign data. Although the synergy of active with passive remote sensing has been extensively tried mainly using the sunphotometer data as ancillary information for the lidar retrieval (e.g. [2; 3]), with GARRLiC algorithm it is the first time that sunphotometer and lidar measurements are both incorporated in the retrieval of the particle microphysical properties. In [1] it is shown that GARRLiC manages to characterize successfully cases of dust mixed with urban or smoke aerosols.

\section{METHODOLOGY}

GARRLiC algorithm retrieves the aerosol concentration profiles along with their columnar microphysical properties, building on the AERONET operational retrieval [4] by ingesting vertically-resolved elastic lidar measurements in the retrieval scheme. This way it utilizes both the columnar information of the sun and sky measurements at four wavelengths and 35 angles from the sunphotometer, together with the vertically-resolved lidar measurements of the elastic backscatter at three wavelengths. GARRLiC input and output is shown in Figure 1.

The lidar measurements during the CHARADMExp campaign were acquired with the Polly ${ }^{\mathrm{XT}}$ OCEANET lidar, provided by the TROPOS Institute (http://www.tropos.de/). The sunphotometer measurements were provided by the Cimel CE318 sunphotometer. 


\begin{tabular}{|c|c|c|}
\hline \multicolumn{3}{|c|}{ GARRLiC algorithm } \\
\hline INPUT & OUTPUT & \\
\hline \begin{tabular}{l}
\multicolumn{1}{c}{ lidar } \\
elastic backscatter signals \\
(range-resolved at 355, 532, $1064 \mathrm{~nm}$ )
\end{tabular} & $\begin{array}{l}\text { for fine and coarse particles } \\
\text { - concentration profile } \\
\text { - size distribution }\end{array}$ & 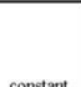 \\
\hline $\begin{array}{l}\text { - AOD sunphotometer } \\
\text { - total scattered radiances } \\
\text { (at } 440,670,870,1020 \mathrm{~nm} \\
\text { and multiple angles }(\leq 35))\end{array}$ & $\begin{array}{l}\text { - real part of refractive index } \\
\text { - imaginary part of refractive index } \\
\text { - spherical particle fraction }\end{array}$ & $\begin{array}{l}\text { constant } \\
\text { along the } \\
\text { column }\end{array}$ \\
\hline
\end{tabular}

Figure 1: GARRLiC algorithm input and output parameters.

Furthermore, in order to identify the origin of the aerosol layers we employed source - receptor computations derived with dispersion modeling tools. These tools provided the source apportionment of the particles in the layer. The modeling simulations were performed with the atmospheric dispersion model FLEXPART-WRF [5], offline coupled with the atmospheric model WRF_ARW [6].

\section{RESULTS}

\section{Dust case}

On June 26 the Polly ${ }^{\mathrm{XT}}$ OCEANET measurements of volume depolarization ratio at $532 \mathrm{~nm}$ showed a plume of non-spherical particles extending from close to the ground up to $5-6 \mathrm{~km}$ (Figure 2).

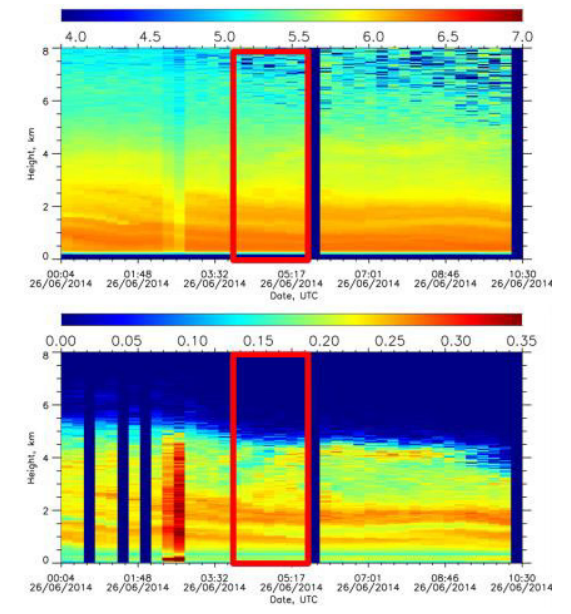

Figure 2: Atennuated backscatter at $1064 \mathrm{~nm}$ in arbitrary units (top) and volume depolarization ratio at $532 \mathrm{~nm}$ (bottom) from Polly ${ }^{\mathrm{XT}}$ OCEANET lidar, on June 26. The red rectangle indicates the time range of the measurements used for GARRLiC retrieval (04:0006:00 UTC).
The AERONET products indicate dust particles, with aerosol optical depth (AOD) at $550 \mathrm{~nm}$ of $\sim 0.4$, Ångstrom exponent at 440/870 nm of $\sim 0.1$ and a coarse-mode dominated size distribution. Dust transport simulations from the NMMB/BSCDust model [7] show Saharan dust transport in Finokalia, which is also supported from our source apportionment modelling in Figure 3: from the ground up to $6 \mathrm{~km}$ the particles are originated from west Sahara with some mixing with particles from the Eastern Mediterranean region, the Balkans and Greece up to $1 \mathrm{~km}$.

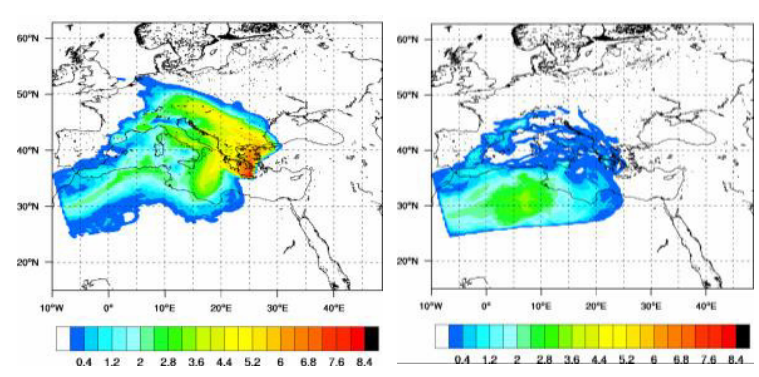

Figure 3: FLEXPART-WRF emission sensitivity (residence time) $\left[\log _{*} \mathrm{~S} \cdot \mathrm{m}^{3} \cdot \mathrm{kg}^{-1}\right]$, at $0-1 \mathrm{~km}$ (left) and 3$6 \mathrm{~km}$ (right), at Finokalia station, on June 26.

GARRLiC retrieved successfully the dust lidar ratio at $532 \mathrm{~nm}$, as seen from the comparison with the Raman retrieval in Figure 4. Moreover, the retrieved size distribution and spectral refractive index for coarse particles agree well with climatological values for dust (e.g. [8]), as well as with AERONET (Figure 5). The AERONET retrieval is closer to the coarse particle characteristics, since this is the dominant mode along the atmospheric column.

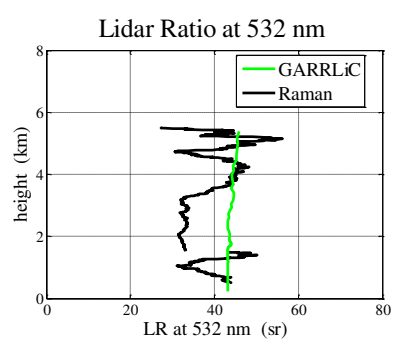

Figure 4: GARRLiC (green line, at 04:00-06:00 UTC) compared with Raman (black line, at 00:00-02:00 UTC) retrieval for the lidar ratio at $532 \mathrm{~nm}$, at Finokalia station, on June 26. 

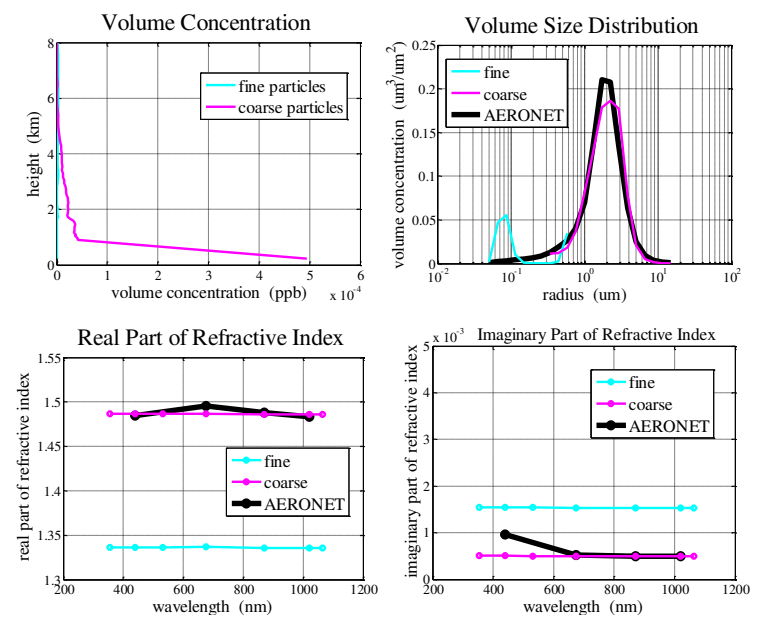

Figure 5: GARRLiC retrieval of particle concentration profiles (up-left), size distribution (up-right), spectral real and imaginary part of the refractive index (bottom -left and right), for fine (cyan) and coarse (pink) particles, at Finokalia station, on June 26, 04:00-06:00 UTC. The black line shows the AERONET retrieval at 04:54 UTC.

\section{$\underline{\text { Dust and marine case }}$}

On July 6 two very distinct aerosol plumes were measured at Finokalia: a depolarizing dust plume at 2-6 $\mathrm{km}$ and a non-depolarizing, possibly containing marine and inland-transported particles plume, extending from the ground up to $1 \mathrm{~km}$ (Figure 6).

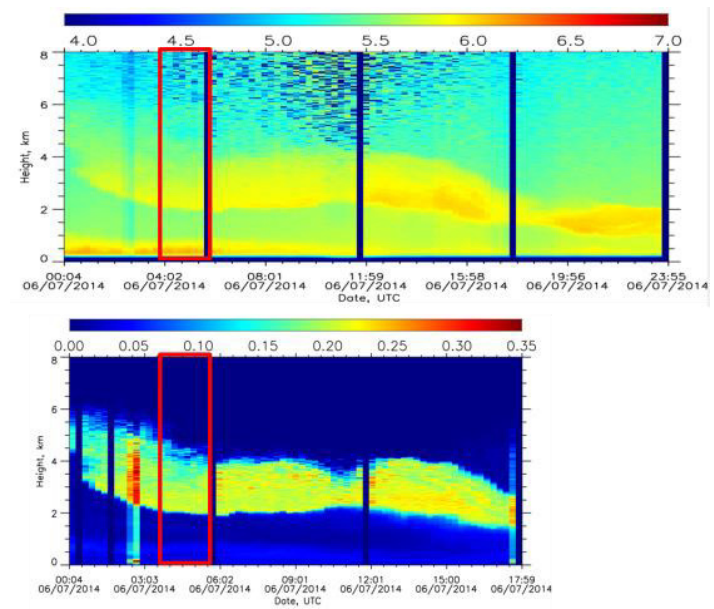

Figure 6: As in Figure 2 for the PollyXT OCEANET lidar measurements on July 6.

The NMMB/BSC-Dust model shows Saharan dust transport over Finokalia, and our source apportionment calculations show mostly Saharan dust particles at $3-4 \mathrm{~km}$ and marine particles (mostly from Aegean Sea) along with particles from the Balkans region at 0-1 km (Figure 7).

Based on the above we expect a dust plume aloft and a plume containing (mostly) marine particles close to the ground. GARRLiC retrieves these two coarse particle dominated layers (see concentration profiles in Figure 9) but it cannot characterize them effectively in terms of their refractive indices, since it is able to retrieve only one refractive index for the coarse mode. Thus what we get from GARRLiC is possibly closer to the average of the refractive indices of dust and marine particles.
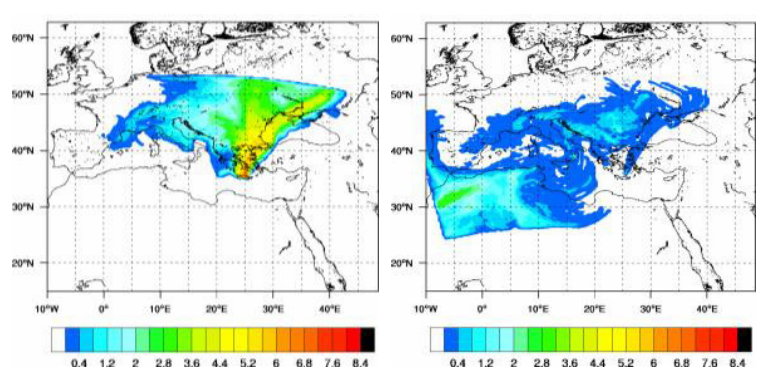

Figure 7: As in Figure 3 for FLEXPART-WRF emission sensitivity on July 6.

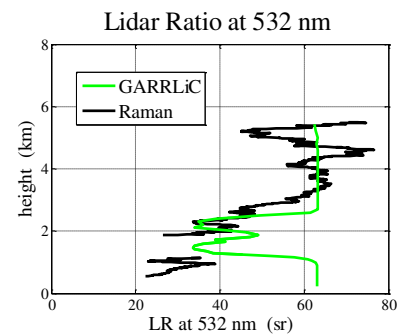

Figure 8: As in Figure 4 for the LR retrievals on July 6.
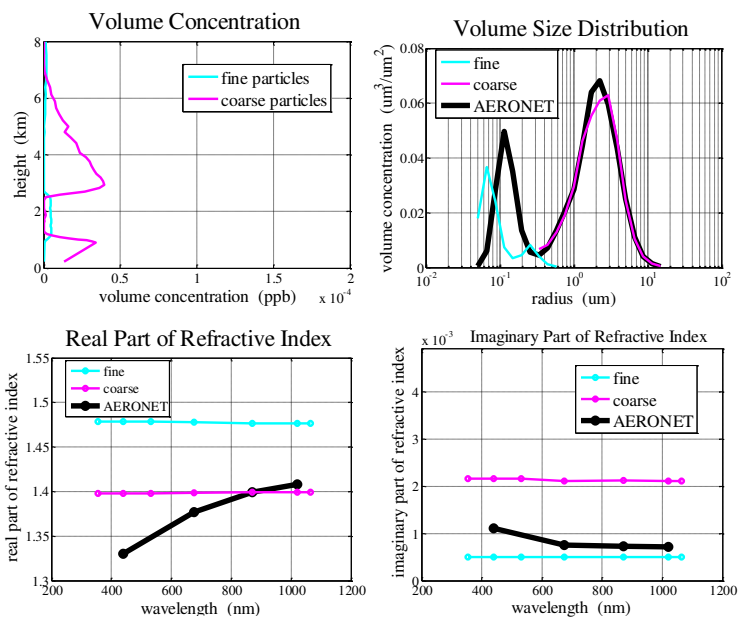

Figure 9: As in Figure 5, for GARRLiC retrieval on July 6, 04:00-06:00 UTC. The black line shows the AERONET retrieval at 05:49 UTC. 
This is what we see in Figure 8 as well, showing that both layers are characterized with the same lidar ratio at $532 \mathrm{~nm}$ from GARRLiC. For the aloft dust plume it matches well the lidar ratio from Raman technique, but for the layer close to the surface, the Raman lidar ratio is much lower, as expected for marine particles.

\section{CONCLUSIONS and FUTURE WORK}

GARRLiC algorithm provides the great innovation of retrieving the vertical profile of aerosol particles utilizing the elastic backscatter lidar measurements together with the sunphotometer measurements in the retrieval. This way it can effectively characterize the particles of fine and coarse modes in terms of their size, shape and refractive index.

In this study we used GARRLiC algorithm to characterize two cases from the CHARADMExp campaign, one with pure dust and one with dust and marine particles. For the first case GARRLiC achieves a successful characterization of the dust vertical distribution and microphysichal properties that seems to agree well with climatological values for dust and Raman retrievals. For the second case the retrieval was not as successful, since GARRLiC is able to discern the properties of fine and coarse particles but not of two different coarse modes.

The retrieval of multiple modes would be possibly feasible in the future with the incorporation of polarimetric measurements from the sunphotometer or Raman signals from the lidar. We aim to continue investigating the GARRLiC potential for aerosol characterization and follow related improvements in the framework of the ACTRIS-2 project and the experimental campaigns that are dedicated to that objective.

\section{ACKNOWLEDGEMENT}

This work has been developed under the auspices of the ESA-ESTEC project "Characterization of Aerosol mixtures of Dust And Marine origin" contract no. IPL-PSO/FF/lf/14.489. The publication was supported by the European Union Seventh Framework Programme (FP7-REGPOT2012-2013-1), in the framework of the project BEYOND, under Grant Agreement no. 316210 (BEYOND - Building Capacity for a Centre of Excellence for EO-based monitoring of Natural
Disasters). The research leading to these results has received funding from the European Union Seventh Framework Programme (FP7/2007-2013) under grant agreement no. 262254 (ACTRIS)

\section{REFERENCES}

[1] Lopatin, A., et al., 2013: Enhancement of aerosol characterization using synergy of lidar and sun-photometer coincident observations: the GARRLiC algorithm, Atmos. Meas. Tech., 6, 2065-2088, doi:10.5194/amt-6-2065-2013.

[2] Fernald, F. G., et al., 1972: Determination of aerosol height distributions by lidar, J. Appl. Meteorol., 11, 482-489, 1972.

[3] Chaikovsky, A., et al., 2012: Combined lidar and radiometric sounding of atmospheric aerosol: algorithm of data processing, software, dessimination, Proceedings of XVIII International symposium "Atmospheric and ocean optics. Atmosphere physics", 2-6 July 2012, Irkutsk, Russian Federation, C1-C4.

[4] Dubovik, O. and King, M, 2000: A flexible inversion algorithm for retrieval of aerosol optical properties from Sun and sky radiance measurements, J. Geophys. Res., 105, 2067320696, doi:10.1029/2000JD900282.

[5] Brioude, J., et al., 2013: The Lagrangian particle dispersion model FLEXPART-WRF version 3.1, Geosci. Model Dev., 6, 1889-1904, doi:10.5194/gmd-6-1889-2013.

[6] Skamarock, W. C., et al., 2008: A description of the Advanced Research WRF version 3, NCAR Technical Note 475.

[7] Basart, S., et al., 2012: Development and evaluation of the BSC-DREAM8b dust regional model over Northern Africa, the Mediterranean and the Middle East, Tellus B, 64, 18539, doi:10.3402/tellusb.v64i0.18539.

[8] Dubovik, O., et al., 2002: Variability of absorption and optical properties of key aerosol types observed in worldwide locations, J. Atmos. Sci., 59, 590-608. 